\title{
Effects of Injection Timing on Mixture Distribution in a Liquid-Phase LPG Injection Engine for a Heavy-Duty Vehicle*
}

\author{
Yonggyu LEE ${ }^{* *}$, Changup $\mathrm{KIM}^{* *}$, Seungmook $\mathrm{OH}^{* *}$ and Kernyong KANG ${ }^{* *}$
}

Effects of injection timing on mixture distribution were investigated in a liquid phase LPG injection engine for a heavy-duty vehicle. An optically accessible engine was made for planar laser induced fluorescence and flame imaging. Mixture distributions around the spark plug were quantified and compared for open and closed valve injection. Two-dimensional flame images were taken to investigate the effect of mixture stratification on flame propagation. In addition, the overall engine performance and emissions were compared for the injection timings at a selected condition. Unlike the case of closed valve injection, where a nearly homogeneous mixture is formed near the spark plug and the flame moves with swirl, in the case of open valve injection, a cloud of richer mixture than overall excess air ratio is formed near the spark plug and the flame moves in the direction of the rich mixture, which extends the limit of lean burn operation.

Key Words: Liquid Phase LPG Injection, Injection Timing, Mixture Stratification, PLIF, Heavy-Duty Engine, Flame Propagation, Port Injection

\section{Introduction}

Liquid Petroleum Gas (LPG) is well known as a clean alternative fuel for vehicles because its higher ratio of $\mathrm{C}$ to $\mathrm{H}$ reduces the amount of $\mathrm{CO}_{2}$ and other non-regulated emissions, such as formaldehyde and acetaldehydes. In an attempt to decrease air pollution in urban areas, several LPG engines have been developed for heavy-duty vehicles and have replaced some diesel engines.

There are several types of LPG fuel supply system, which range from gas vaporization with an open-loop control system to liquid injection with a closed-loop control system ${ }^{(1)}$. Most commercially available LPG engines adopt a mixer type system, which supplies gas fuel into the intake air upstream of the throttle body with a vaporizer. The gas phase port injection system has reduced the problems of cold start and response in transient air-fuel ratio control in light- and middle-duty vehicles. Recently, the liquid phase LPG injection (LPLI) system was considered as one of the next-generation fuel supply systems for heavy-duty vehicles. Due to high volatility and latent heat of evaporation of LPG (20\% higher compared with gaso-

\footnotetext{
* Received 25th December, 2002 (No. 02-5207)

** LP GAS Engine Task Force Team, Korean Institute of Machinery and Materials, 171 Jang-dong, Yuseong-gu, Daejeon 305-343, Korea. E-mail: cukim@kimm.re.kr
}

line), the LPLI system has several advantages over other systems, e.g., (1) enhancement of volumetric efficiency, (2) reduction of exhaust gas temperature and amount of $\mathrm{NO}_{x}$ emissions, (3) prevention of backfire, and (4) extension of knock limit ${ }^{(2)}$. However, when the LPLI system is applied to heavy-duty engines, several challenges arise to satisfy fuel economy, performance, and emission regulations, such as optimization of the design of the combustion chamber and intake port ${ }^{(3)}$.

Lean burn strategy has been considered as one of the methods to meet these requirements ${ }^{(4)}$. Even though a lean burn strategy is required for heavy-duty LPG engines, particularly to relieve thermal load at retarded ignition condition, to avoid engine knock $^{(5)}$, it might cause unstable operating conditions such as severe cyclic variation, misfire, and partial burn. Fuel stratification is well known as a key technology to extend lean limit, and generally it can be achieved by injection timing control and optimizing combustion chamber design to generate adequate swirl and squish flow.

In this work, the effects of injection timing on mixture distribution in an LPLI heavy-duty engine were investigated with a single-cylinder engine. Open valve injection (OVI) and closed valve injection (CVI) have been compared to determine the effects of the in-cylinder fuel distribution. Mixture distributions around the spark plug during 
the compression period were quantified and compared for both injection times using the PLIF technique, and twodimensional flame propagation images were recorded in an optically accessible engine.

\section{Experimental Methods}

A naturally aspirated compression ignition engine (six cylinders, displacement volume of $11 \mathrm{~L}$, and bore of $130 \mathrm{~mm}$ ) was converted into a spark ignition LPG-fueled single-cylinder engine. The compression ratio was modified down from 16.5 to 9.3 and a spark plug was inserted in place of the injector. Only the first cylinder was operated. Other cylinders were covered with steel plates and not used, and a DC dynamometer was directly coupled with the engine. LPG fuel, which is a mixture of $60 \%$ propane and $40 \%$ butane by mass, was used throughout the work.

Figure 1 shows a schematic diagram of the engine setup. In order to maintain LPG in liquid phase through the fuel supply line, a fuel tank was pressurized above $1 \mathrm{MPa}$ with nitrogen, and temperature and pressure in the fuel line were monitored. A bottom feed-type LPLI injector (Siemens, DEKA II), which enables any bubble that might generate around the injector tip to float up-and-out and prevent vapor lock, was used. Air and fuel flow were measured with a laminar flow meter (Meriam, 50MY15) and an electronic balance, respectively, and confirmed by a UEGO (universal exhaust gas oxygen) sensor installed in the exhaust manifold. A spark plug-type pressure transducer was installed for combustion analysis, and engineout emissions were analyzed with an exhaust gas emission analyzer (Horiba, MEXA8120D). In addition, four thermocouples were installed in the intake manifold to monitor the temperature drop due to evaporation of fuel.

For PLIF and flame imaging, an optical singlecylinder engine was made, in which bottom views of the combustion chamber are optically accessible through a quartz liner and piston. Figure 2 shows a schematic diagram of the experimental setup. A KrF Excimer laser (wave length of $248 \mathrm{~nm}$, pulse width of $20 \mathrm{~ns}$, line width less than $5 \mathrm{pm}$ ) and a fast scan ICCD camera (Stanford Computer Optics, 4Quik05) were used for PLIF imaging, and a 48-mm-wide laser sheet beam was generated at $22 \mathrm{~mm}$ below the bottom of the cylinder head as shown in Fig. 3. A WG305 filter was placed in front of the ICCD camera to block light from the Mie scattering and interference with inner reflections. Since a commercial heavyduty diesel engine was modified into an LPLI spark ignition engine, the engine head was flat, and about $35 \%$ of the combustion chamber area was viewed from the bottom by the high speed camera for natural light flame imaging as shown in Fig. 3. A high-speed gated image intensifier was used and its gain and exposure time were adjusted for lean flames.

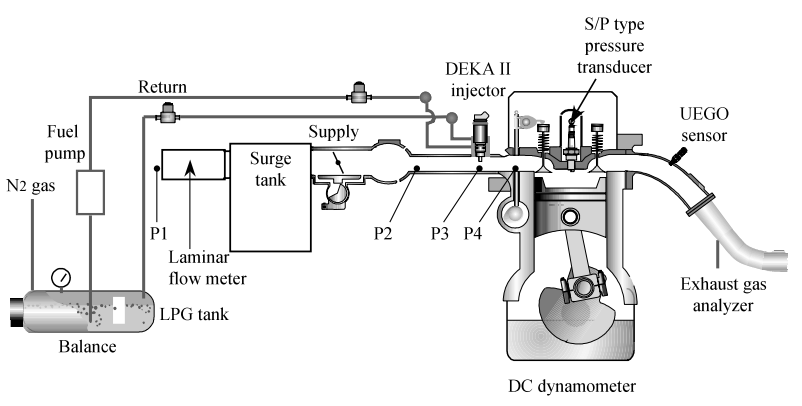

Fig. 1 Schematic diagram of engine setup

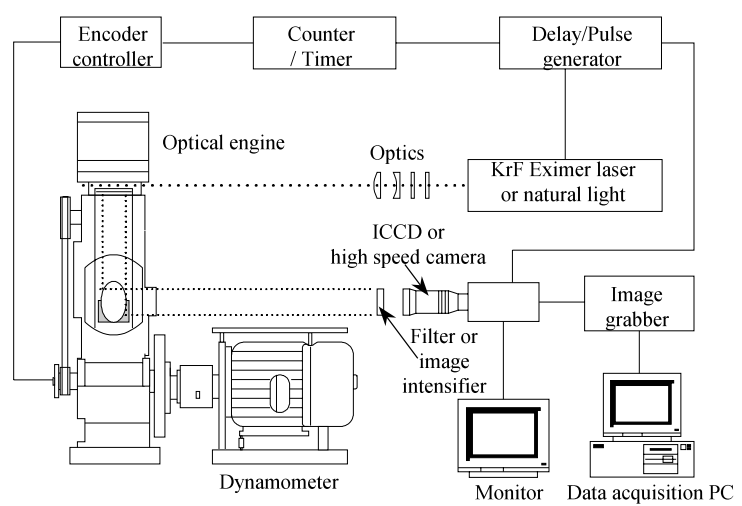

Fig. 2 Schematic diagram of single engine setup for PLIF and flame imaging

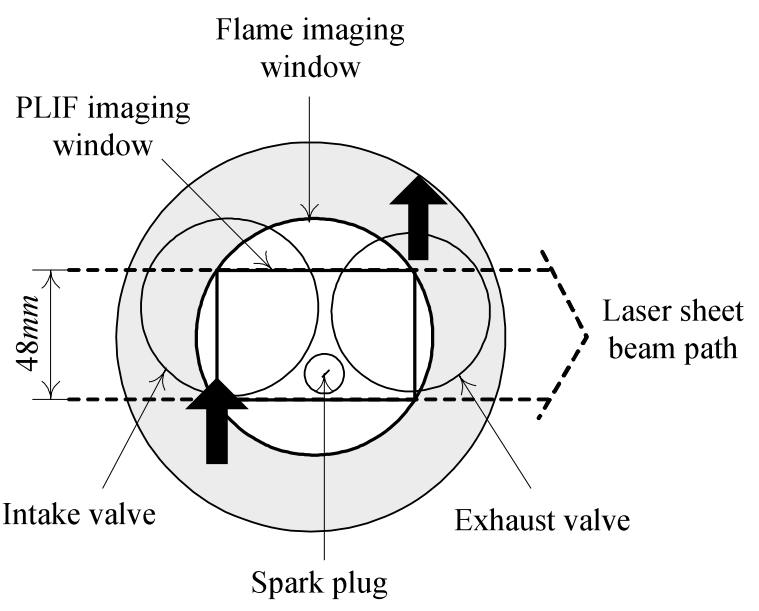

Fig. 3 Bottom view of combustion chamber

Because pure LPG fuel does not generate fluorescence by transition from the excited state, acetone, which comprised $20 \%$ volume of the fuel at a given excess air ratio $(\lambda)$, was doped in the air and fuel mixture. Even though acetone is different from LPG in respect to its physical properties, it is frequently used as a dopant for gasolineand CNG-fueled engines because of its relatively low boiling point, being non-toxic, and its rare quenching by oxygen $^{(6),(7)}$. To quantify the mixture strength from PLIF images, several sources of error should be corrected, namely, (1) variation of the laser power, (2) spatial non-uniformity of the laser sheet beam, (3) distortion due to the curvature 


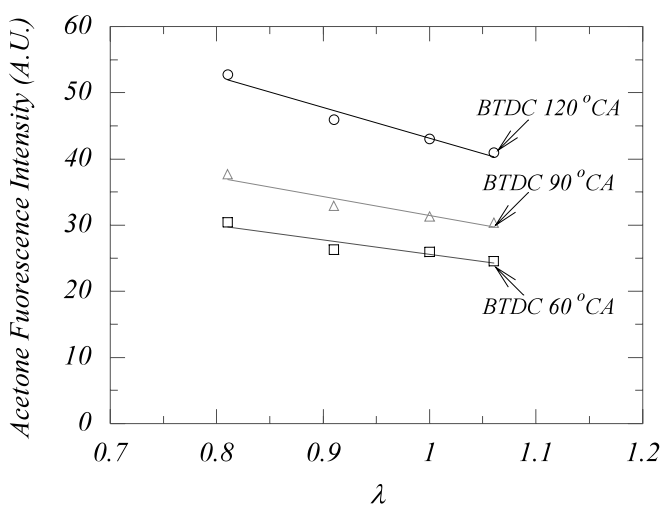

Fig. 4 Linear correlations for acetone fluorescence intensity with excess air ratio at different crank angles at condition of engine speed of $500 \mathrm{rpm}$ and $20 \%$ of WOT

of quartz, and (4) difference in sensitivity of the ICCD elements.

In this work, using a beam splitter, $5 \%$ of laser power is split and used as the reference signal for every image to correct variations of laser power and synchronization errors. For background noise, 50 un-fueled fluorescence images were ensemble averaged for given crank angles and subtracted from each acetone fluorescence image. In order to compensate for the difference in sensitivity of every pixel for the given crank angles, correlations for CCD elements were made by comparing every pixel of fluorescence images for uniform mixtures and normalizing it with 50 ensemble averaged images.

After all corrections explained above were applied, the linear correlations for acetone fluorescence intensity for homogeneous mixtures were made, as shown in Fig. 4, at selected crank angles during the compression period at the condition of engine speed of $500 \mathrm{rpm}$ and $20 \%$ of wide open throttle (WOT). Since the intensity of acetone fluorescence depends upon the number density of acetone, temperature and pressure, in real engine conditions, it had to be corrected for every crank angle and excess air ratio.

\section{Results and Discussion}

When liquid phase LPG is injected into the intake port, due to high volatility and latent heat of evaporation, it cools the surrounding intake air. The cooler intake air not only increases the mixture charge density, which leads to greater engine output, but also lowers the peak temperature of burned gas, to reduce the amount of $\mathrm{NO}_{x}$ emissions. Figure 5 shows the variations of intake air temperature according to the fuel supply systems at the condition of $1200 \mathrm{rpm}$, WOT, excess air ratio of 1.0. Measured positions are indicated in Fig. 1. A commercial 2L mixer system with vaporizer was installed for the purpose of comparison. Fuel was injected at $78^{\circ} \mathrm{CA}$ (crank angle degree) after intake valve opens, and $30^{\circ} \mathrm{CA}$ after intake valve closes for OVI and CVI, respectively. Temperatures

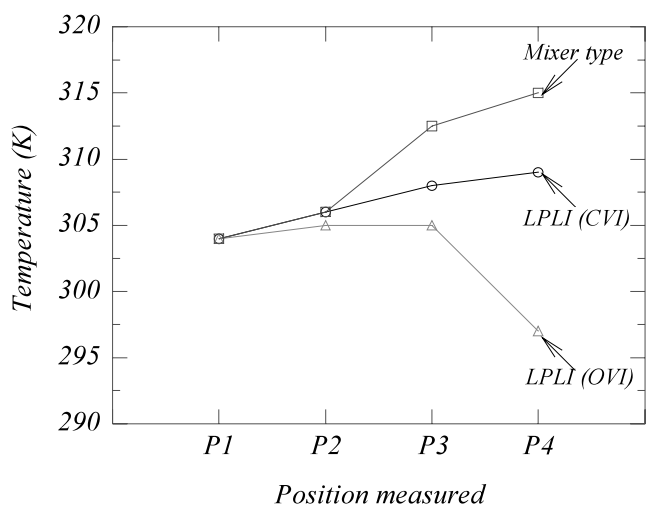

Fig. 5 Comparisons of temperatures in the intake manifold between mixer system and liquid phase LPG injection system

in the manifold increase as it gets closer to the combustion chamber, but in the case of OVI in the LPLI system, it drops because liquefied fuel with a high latent heat of evaporation, evaporates quickly. According to the rig test of injection, Mie scattering images confirmed that fuel evaporates fully at $8 \mathrm{~ms}$ after the end of injection, which is equivalent to $28.8^{\circ} \mathrm{CA}$ at this engine speed. In addition, since injection occurs while the intake valve is open, $\mathrm{LPG}$ fuel stays for a shorter time in the manifold and the intake air gets less heat transfer from the intake manifold and the combustion chamber than in the case of CVI.

Figure 6 shows the 50 cycles ensemble averaged twodimensional mixture distributions near the spark plug during the compression period for different injection timings at the condition of $500 \mathrm{rpm}$ engine speed, $20 \%$ of WOT, Ricardo swirl ratio of 2.3, and excess air ratio of 1.0. In the case of CVI, a cloud of slightly rich mixture moves around with swirl, and at $60^{\circ} \mathrm{CA}$ before top dead center (BTDC), which is equivalent to $30^{\circ} \mathrm{CA}$ before ignition at this condition, the cloud of slightly rich mixture $(\lambda \approx 0.9)$ entrained at an earlier stage of the intake process passes under the spark plug shown in Fig. 6(a), and moves towards the intake valve. An almost uniform stoichiometric mixture is formed around the spark plug, by the squish flow generated by the bowl in the piston, due to mixing with the lean mixture entrained at a later stage of intake process. In the case of OVI, a cloud of rich mixture $(\lambda \approx 0.6)$ forms at the intake valve side and moves with swirl, keeping the mixture rich around the spark plug. Since injection occurs at the maximum lift of the valve, the cloud of rich mixture is entrained later than in the case of CVI and forms a rich mixture around the spark plug. In spite of mixing by the squish flow, the stratified mixture distribution is retained during the compression period. Even though these images are 50 cycles averaged, it is clear that fuel stratification near the spark plug is achieved in the case of OVI, which might contribute to the extension of the lean limit. According to Nogi et al. ${ }^{(8)}$, strong air flow distorts the spray 


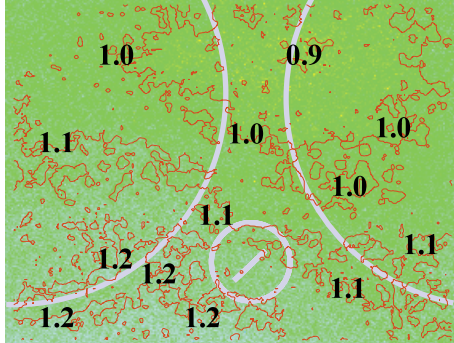

BTDC $120^{\circ} \mathrm{CA}$

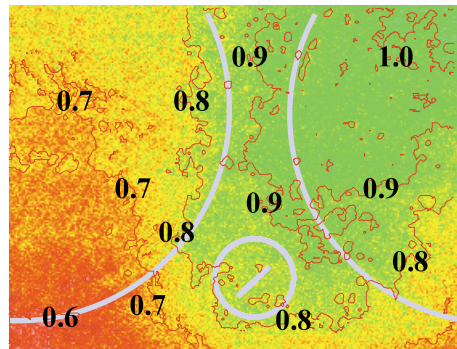

BTDC $120^{\circ} \mathrm{CA}$

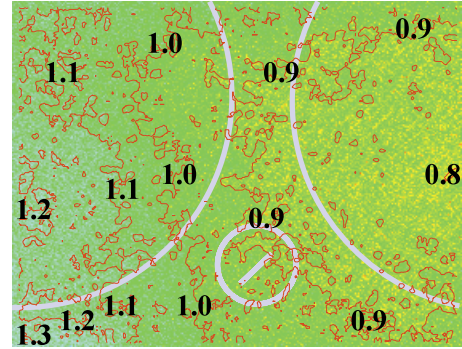

BTDC $90{ }^{\circ} \mathrm{CA}$

(a)

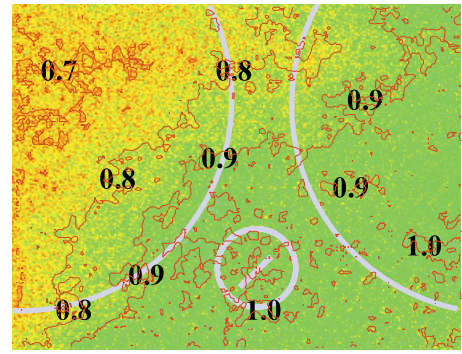

BTDC $90^{\circ} \mathrm{CA}$

(b)

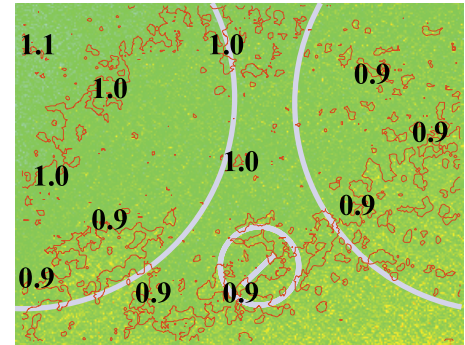

BTDC $60{ }^{\circ} \mathrm{CA}$

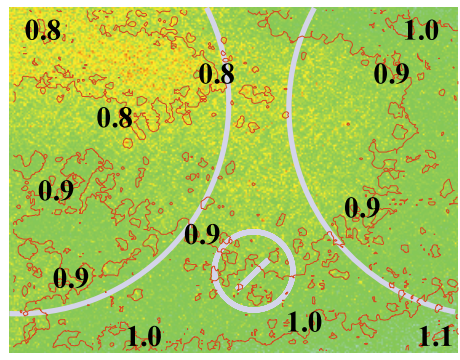

BTDC $60{ }^{\circ} \mathrm{CA}$

Fig. 6 Two-dimensional distribution of in-cylinder excess air ratio during the compression period at the condition of engine speed of $500 \mathrm{rpm}$, overall excess air ratio of 1.0, and $20 \%$ of WOT, (a) closed valve injection, (b) open valve injection

pattern in the case of OVI and might cause mixture maldistribution in a gasoline-fueled engine. However, this is not true in the case of an LPLI engine. Since a heavy-duty diesel engine was modified into a spark ignition LPLI engine, its intake port is helical and the injector is targeting the port not the valve. Moreover, LPG fuel evaporates more quickly than gasoline. That is why the vapor of LPG fuel follows the main air stream along the helical port and stratifies the mixture around the spark plug.

To investigate the effect of mixture stratification, flame images were recorded at every $3^{\circ} \mathrm{CA}$ with a high speed camera at the condition of engine speed of $500 \mathrm{rpm}$, $20 \%$ of WOT, overall excess air ratio of 1.2 , and spark timing of BTDC $30^{\circ} \mathrm{CA}$. Figure 7 shows typical examples of flame contours with crank angles for both the case of CVI and of OVI. For the case of OVI, it is clear that rich mixtures formed near the spark plug contribute to the shorter flame development period, even though flame images are only two-dimensional and do not have any information along the cylindrical axis. Unlike the case of CVI, where the 10 cycles averaged geometric center of the flame moves with swirl, the trajectory of the flame center moves upward as shown in Fig. 7 (c). This might be due to mixture stratification, in which case a cloud of rich mixture stays on the upper side of the spark plug as shown in Fig. 6. This will also lead to an extension of knock limit by decreasing the flame arrival time on the end gas region ${ }^{(9)}$. Eventually, the flames follow the direction of swirl.

Figure 8 shows the 10 cycles averaged speeds of the

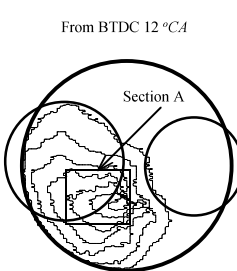

(a)

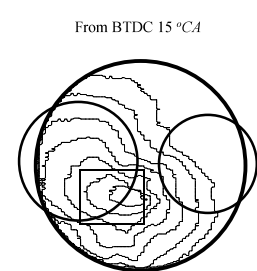

(b)

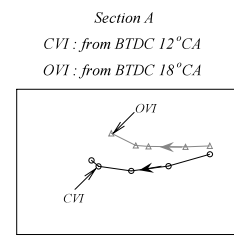

(c)
Fig. 7 Flame contours with crank angles at the condition of the engine speed of $500 \mathrm{rpm}$, overall excess air ratio of 1.2, the spark ignition time of $30 \mathrm{BTDC}{ }^{\circ} \mathrm{CA}$, and $20 \%$ of WOT, (a) closed valve injection, (b) open valve injection, (c) comparisons of 10 cycle averaged trajectories of the geometric flame centers

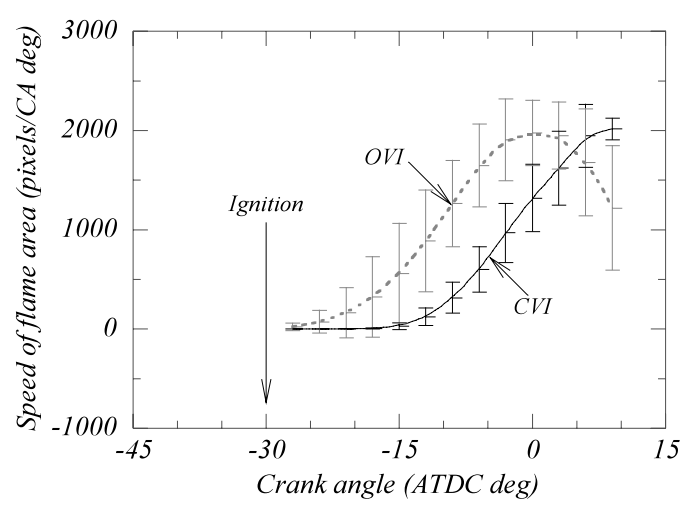

Fig. 8 Comparisons of 10 cycle averaged speed of flame area with the injection timing at the same condition as for Fig. 7 


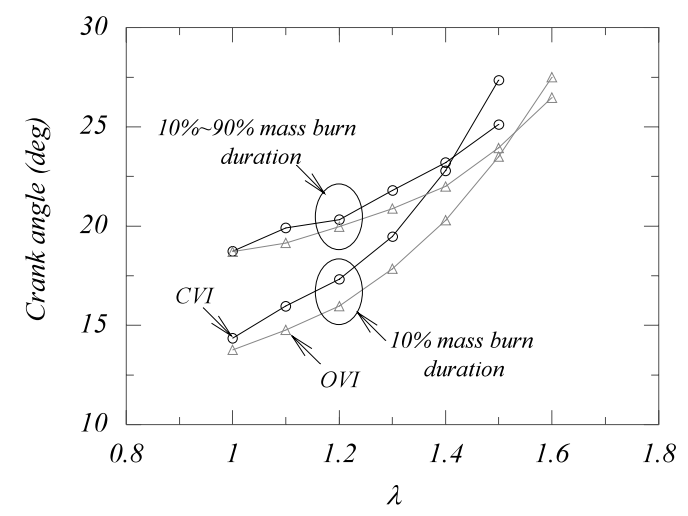

Fig. 9 Comparisons of mass burn duration according to injection timing with excess air ratio at the condition of engine speed of $1200 \mathrm{rpm}$, WOT, and, excess air ratio of 1.2

flame area, with crank angles for both CVI and OVI. Clearly, for the case of OVI, the flame development period is much shorter than that of CVI, which is a benefit of the stratified mixture ${ }^{(10)}$. Interestingly, the slopes of 2D flame area speed are similar for the flame development period when flame edges stay within the imaging window, which corresponds to five or six frames after the flame kernel appears. This results in a similar effect to spark-time advancement and increases the engine output.

Figure 9 shows the mass burn durations with injection timings at the condition of engine speed of $1200 \mathrm{rpm}$ and WOT. As the mixture becomes leaner, the differences in $10 \%$ mass burn duration increase, which means that for the lean mixtures, stratification makes the initial flame kernel more stable than that in the homogeneous mixture. Interestingly, this difference decreases as the flame develops into the main combustion period (10-90\% mass burn duration). Since overall equivalence ratios are the same, initially stratified flame develops faster but the flame speed decreases as it moves into the leaner zone. For the case of CVI, this longer initial flame development period in a homogenous lean mixture might lead to misfire and make engine operation unstable.

Figure 10 shows the coefficient of variation for indicated mean effective pressure (COV_imep), and efficiencies with injection timings at the same condition as for Fig. 9. For the case of CVI, as the mixture gets lean by as much as $1.5, \mathrm{COV}$ imep increases abruptly by more than $5 \%$, which is the criterion for stable engine operation. Due to mixture stratification, keeping efficiency the same, the lean limit is extended from 1.4 to 1.5 in the case of OVI.

Figure 11 shows the engine-out emissions with injection timing at the same condition as for Fig. 9. Since initial flame development is faster and burned gas temperature is higher in the case of OVI, the amount of $\mathrm{NO}_{x}$ emissions slightly increases. However, the amount of $\mathrm{HC}$ emissions remains similar as in the case of CVI. This is a noticeable difference of LPG-fueled engines when com-

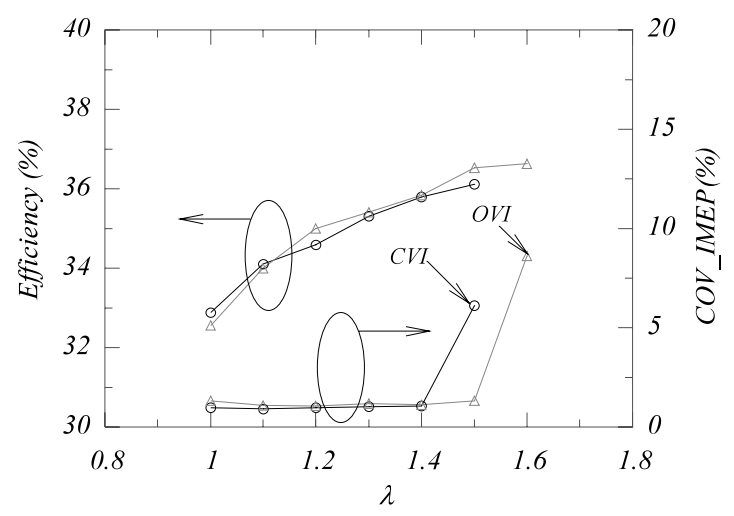

Fig. 10 Comparisons of efficiencies and COV_imeps according to injection timing and excess air ratio at the same condition as for Fig. 10

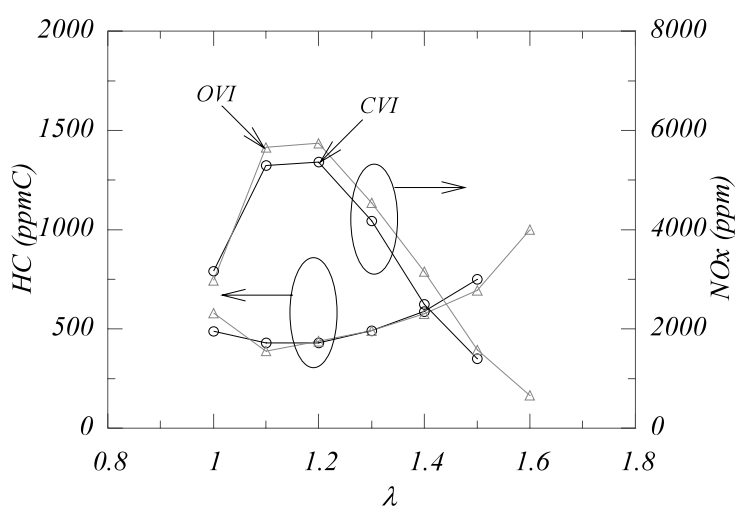

Fig. 11 Comparisons of $\mathrm{HC}$ and $\mathrm{NO}_{x}$ emissions according to injection timing and excess air ratio at the same condition as for Fig. 11

pared with gasoline engines. Generally, for gasoline engines, the amount of $\mathrm{HC}$ emission increases due to fuel wetting and mal-distribution of mixture ${ }^{(8)}$. However, LPG fuel has high volatility and has negligible effect of fuel wetting on the valve and cylinder wall, which leads to $\mathrm{HC}$ emissions being maintained at the same level.

\section{Conclusions}

A liquid phase LPG injection engine for a heavy-duty vehicle was developed by modifying a commercial diesel engine. To investigate the effects of injection timing in an LPLI engine, in-cylinder mixture distribution was measured with the PLIF imaging technique, and flame propagation images were taken with a high-speed camera in an optical single-cylinder engine. To compare the performance of the engine, injection timing and excess air ratio were changed at a selected condition. The following conclusions were obtained.

1. In the case of open valve injection, the temperature of intake air is much lower than in the case of closed valve injection and mixer system, due to high volatility and latent heat of evaporation, and shorter residence time of fuel in the manifold, which will increase the engine output. 
2. In the case of open valve injection, the initial flame development period is shorter than in the case of closed valve injection due to the mixture stratification, and initially the geometric center of the flame moves toward the direction in which mixture is rich, whereas the flame follows the direction of swirl in the case of closed valve injection.

3. Unlike gasoline engines, open valve injection in a liquid phase LPG injection engine does not increase the amount of $\mathrm{HC}$ emissions because the high volatility of LPG fuel decreases the chance of fuel wetting on the valve and combustion chamber.

\section{Acknowledgements}

The authors would like to thank the Korean Ministry of Science and Technology for funding this research through a national research laboratory (NRL) project.

\section{References}

(1) World LP Gas Association, Automotive LP Gas Today's Fuel For a Cleaner Tomorrow, 3rd Edition, (1998).

( 2 ) Kang, K., Lee, D., Oh, S. and Kim, C., Performance of a Liquid Phase LPG Injection Engine for Heavy Duty Vehicles, SAE Paper No.2001-01-1958, (2001).

( 3 ) Goto, S., Lee, D., Shakal, J., Harayama, N., Honjyo, F. and Ueno, H., Performance and Emissions of LPG
Lean Burn Engines for Heavy Duty Vehicles, SAE Paper No.1999-01-1513, (1999).

( 4 ) Gomes, A. and Reinke, P., Lean Burn: A Review of Incentives, Methods, and Tradeoffs, SAE Paper No.880291, (1988).

( 5 ) Weide, J.V.D., Seppen, J.J., Ling, J.A.N.V. and Dekker, H.J., Experiences with CNG and LNG Operated Heavy Duty Vehicles with Emphasis on US HD Diesel Emission Standards, SAE Paper No.881657, (1988).

( 6 ) Thurber, M.C., Grisch, F., Votsmeier, B.J. and Hanson, M., Measurements and Modeling of Acetone LaserInduced Fluorescence with Implications for Temperature Imaging Diagnostics, Applied Optics, Vol.37, No.21 (1998), pp.4963-4978.

( 7 ) Hiltner, J. and Samimy, M., The Impact of Injection Timing on In-Cylinder Fuel Distribution in a Natural Gas Powered Engine, SAE Paper No.971708, (1997).

( 8 ) Nogi, T., Ohyama, Y. and Yamaguchi, T., Effects of Mixture Formation of Fuel Injection Systems in Gasoline Engines, SAE Paper No.891961, (1989).

( 9 ) Lee, Y., Pae, S., Min, K. and Kim, E.S., Prediction of Knock Onset and the Autoignition Sites in Spark Ignition Engines, Proc. Instn. Mech. Engrs., Vol.214, Part D (2000), pp.751-763.

(10) Moriyoshi, Y., Morikawa, H., Kamimoto, T. and Hayashi, T., Combustion Enhancement of Very Lean Premixture Part in Stratified Charge Conditions, SAE Paper No.962087, (1996). 